\title{
PENSAR A ETNOMATEMÁTICA: O COTIDIANO RURAL COMO LUGAR AUTÊNTICO DE REVELAÇÃO DO CONHECIMENTO
}

\author{
THINKING ETHNOMATHEMATICS: THE RURAL DAILY LIFE \\ AS AN AUTHENTIC PLACE OF REVELATION OF KNOWLEDGE
}

Jândela Cristiani Guilherme dos Santos Tamashiro ${ }^{1}$

Recebido: 20 fev. 2019

Aceite: 18 mai. 2019

DOI https://doi.org/10.29327/2.1373.1-12

RESUMO: O artigo objetiva refletir sobre a Etnomatemática como alternativa para encurtar caminhos, proporcionando uma aprendizagem significativa e prazerosa para os alunos e contribuindo para o pensar pedagógico dos professores de matemática. Buscou-se descrever e compreender um processo pedagógico que estabelece vínculos entre práticas cotidianas da cultura dos alunos de comunidades rurais e a matemática na escola. O estudo busca na Etnomatemática, alternativas para organização de aulas que se mostrem mais atrativas, envolventes e motivadoras para os alunos. Desse modo, as considerações que aqui pretendo fazer, centram-se em alguns elementos que considero expressivos para compreensão do ensino, tendo como ponto de partida a Etnomatemática.

PALAVRAS-CHAVE: Matemática; Etnomatemática; Ensino; Aprendizagem; Cultura.

ABSTRACT: This article aims to reflect upon the Ethnomatemathics as a resource to shorten paths, by providing a meaningful and pleasant learning to the students, also contributing to the Mathematics teacher's pedagogical thinking. Seeking to describe and comprehend a pedagogical process that stablishes a link between daily practices and the culture of the students from rural community. The study chases in the Ethnomatemathics, resources to organize classes that come out more attracting, compelling and inspiring to the students. Therefore, the considerations hereby intended, concentrate in a few elements that I consider significant to comprehend teaching, taking Ethnomatemathics as a starting point.

KEY WORDS: Mathematics; Ethnomathematics; Teaching; Learning; Culture.

\footnotetext{
1 Doutoranda em Educação pela Universidade Federal de São Paulo (UNIFESP). Pedagoga no Instituto Federal de São Paulo (IFSP). E-mail: jandelacristiani@ifsp.edu.br ORCID iD https://orcid.org/0000-0002-6901-158X.
} 


\section{CONSIDERAÇÕES TEÓRICO-METODOLÓGICAS INICIAIS}

Desde os primórdios da humanidade, conforme sentia necessidade de subsistência, o homem buscava a resolução dos seus problemas por meio de estratégias que conduziam à produção de conhecimentos matemáticos. A exemplo disso, pode-se mencionar as cheias do Rio Nilo, que através da reflexão e observação, permitiu aos agricultores chegarem à ideia de fração e Geometria. Ao longo do tempo, o conhecimento vem sendo construído a partir da necessidade da resolução de uma situação-problema do dia a dia dos homens, e com o avanço do uso de novas tecnologias, esse conhecimento se tornou abstrato e representativo, ocupando lugar de destaque, especialmente, nos espaços formais de ensino.

Em função disso, alguns equívocos foram criados e sedimentados, transformando a matemática, em uma disciplina rigorosa e pouco atrativa. Sendo uma disciplina obrigatória, os alunos muitas vezes não demonstram motivação para estudá-la. Parte disso se deve à dificuldade em perceber sua utilidade e aplicação. Essa realidade provoca no mínimo, o surgimento das evasões e reprovações que são indicadores do fracasso escolar.

As discussões envolvendo essa questão, revelam a angústia de alguns professores que dizem não saber mais o que fazer nas aulas de matemática para motivar os alunos. Ainda que esses professores busquem, em outros momentos de formação, respostas para esse problema continuam sentindo dificuldades em relação à organização para o ensino da disciplina.

Ao discutir a Etnomatemática, o professor Ubiratan D’Ambrosio, seu principal idealizador e defensor, ressalta o fato de que ela leva em consideração os fatos e conhecimentos que fazem parte do ambiente cultural no qual os alunos vivem. Os educadores não podem desconsiderar os conhecimentos trazidos dos alunos, das suas comunidades, sua cultura e os seus pensamentos. Nesse sentido, é importante valorizá-los porque será a partir de tais conhecimentos que surgirão novas aprendizagens, refletindo em um sentido mais real e significativo as aulas de matemática.

A sociedade contemporânea tem, em função de suas transformações tecnológicas, exigido uma Escola que forme cidadãos capazes de lidar com os novos desafios do mundo moderno a fim de atender ao desenho deste novo cenário. Com o ensino da matemática não é diferente, sendo 
necessário, então, aproveitar o que o aluno traz de casa e ampliar os seus conhecimentos para que ele seja atuante nos novos modelos desenhados pela sociedade.

O professor não pode nesse contexto globalizante e imperativo se furtar de suas atitudes reflexivas. Pensar o ensino da disciplina compreende, concomitantemente, pensar a aprendizagem dos alunos, alvo maior da Educação. Para tanto, as metodologias necessitam acompanhar a realidade do alunado, buscando coerência e eficácia em sua prática. Assim, a Etnomatemática assume como princípio o contexto cultural dos educandos para, somente então, levá-los a uma aprendizagem significativa dos conteúdos matemáticos e sua inserção consciente no cotidiano de modo que esse passe a ser visto como laboratório de pesquisa para a construção de conceitos fundamentais à disciplina.

Desde a década de 1970, pensadores da educação como D’Ambrósio (1998), Ferreira (1997) e Knijnik (2000) buscam, através desse pensamento, romper com o tradicionalismo acadêmico ao buscar formar cidadãos mais críticos e dotados de reflexão pessoal e social. Dessa forma, o movimento da Etnomatemática configura-se como um novo olhar direcionado à prática cotidiana de sala de aula e ao romper com as orientações prescritivas de alguns manuais de educação, bem como os diversos regimentos que os regulamentam.

O aluno, nessa visão, passa a ser sujeito do conhecimento e, vale salientar, de um conhecimento que supera os limites da teoria pura, uma vez que são vislumbrados em situações corriqueiras, com as quais o educando lida diariamente. O mundo ao seu redor passa a ser um observatório constante e real daquilo que o discurso de seus educadores teorizam. A essência da técnica é, assim, atribuída ao objetivo claro de satisfação do aprendiz aliada à eficiência das metodologias aplicadas no ambiente de aprendizagem.

Independente do lócus de atuação, o perfil do corpo discente é pensado, observado e diagnosticado e a partir disso o professor elabora estratégias de aprendizagem peculiares que correspondam às distintas e diferentes realidades. De acordo com Rohden (1998), somente quem pode contar com o dizer e o fazer social do educando é o professor e cabe a ele, por meio de suas práticas, despertar nesses sujeitos potencialidades ainda não desenvolvidas. Nessa discussão, percebe-se claramente a necessidade de se pensar a educação sob uma perspectiva inclusiva e 
evolutiva enquanto processo contínuo.

A reflexão sobre a Etnomatemática encontra, nesses termos, o respaldo necessário à sua valorização na sala de aula. A visão tradicional do processo pedagógico limita o processo de construção do conhecimento por parte dos educadores e instituições, uma vez que desrespeita a história do educando e sua participação efetiva no todo social. O aluno não é um banco de dados gerido por usuários alheios. Ele vive o processo do conhecer e aprender diariamente e constantemente através das experiências do cotidiano. Pensar a matemática amparada pela realidade cultural dos alunos é fundamental para a criação de metodologias eficazes e para o sucesso da aprendizagem que falamos tanto entre os muros da universidade. A aprendizagem mecânica dos conteúdos, sem uma análise reflexiva de sua aplicabilidade, fez com que o estudo dessa disciplina nos últimos anos sofresse o abandono e o desinteresse próprios de metodologias obsoletas.

Os alunos não são convencidos de que o currículo corresponde a necessidades reais. E os professores, por outro lado, não se deixam convencer de que a utilização de novas metodologias favorecerá o desenvolvimento das aulas e facilitará a resolução dos conflitos educativos.

Em se tratando de alunos oriundos de zonas rurais, percebemos que há um fator diferencial no processo: as relações cotidianas e de trabalho são bastantes distintas daquelas vividas na zona urbana o que provoca a emergência de abordagens diferenciais aos novos problemas que surgem. $\mathrm{O}$ choque cultural entre o que pretende o conteúdo escolar e a realidade do campo é ainda maior.

Para pensar essas questões, assumimos uma abordagem investigativa pautada em uma pesquisa qualitativa. Este tipo de pesquisa, segundo Creswell (2014), permite conduzir a investigação que demanda debruçarmos sobre determinados grupos ou populações e identificando variáveis que não poderiam ser mensuradas facilmente ou, ainda, escutando vozes silenciadas.

Ao longo desta pesquisa foi empregado um questionário aberto que permitiu uma reflexão mais aprofundada dos dados coletados, relacionando-os com o referencial teórico utilizado, aproximando-nos mais do objeto de estudo e mantendo o alcance dos objetivos propostos inicialmente.

A pesquisa teve como lócus uma Escola Municipal situada no do interior do Estado do Rio Grande do Norte, na cidade de Assú. A Escola atende alunos do $6^{\circ}$ ao $9^{\circ}$ ano, das mais diversas 
localidades rurais do município. Dessa forma, optou-se por realizar a investigação por meio da aplicação de questionários no turno matutino, considerando que nele há uma incidência maior do número de alunos da zona rural. Trabalhou-se com uma amostra de 10\% dos alunos de cada turma, das cinco existentes do $6^{\circ}$ ano, sujeitos diretos da pesquisa escolhidos de forma aleatória em cada uma das turmas e uma professora de matemática que atende as referidas classes.

$\mathrm{O}$ intuito era identificar e analisar o perfil metodológico, i.e. a didática, a metodologia e a avaliação da aprendizagem, bem como a possibilidade de empregar a Etnomatemática como prática pedagógica ao longo das aulas de matemática. A partir disso, fez-se uma análise interpretativa dos dados que, juntamente com a pesquisa bibliográfica, constitui o cerne do presente estudo.

\section{UM PERCURSO TEÓRICO NUMA REALIDADE ATUAL}

Desde a década de 1960, ou mesmo ainda antes, os estudiosos da matemática preocupam-se em devolvê-la o seu valor. Observa-se que o ensino da matemática não tem apresentado a rigorosidade que supostamente deveria e a culpa disso, muitas vezes, é atribuída aos professores. Compreende-se que os educadores exercem função essencial no desenvolvimento das potencialidades necessárias em seus educandos para o pleno funcionamento cognitivo sendo uma peça chave nesse processo. No entanto, faz-se necessário entendê-lo não meramente como detentor do conhecimento, mas sim um facilitador de sua produção.

Por essa razão, o desenvolvimento da didática recebeu atenção especial no ensino da matemática, buscando sempre acompanhar o contexto histórico em que se inseria. Nos anos 80, por exemplo, com o advento dos meios de comunicação de massa, os métodos do estudo da matemática receberam maior abrangência e isso foi potencializado nos anos 90 com o acesso à informática. Tais mudanças no cotidiano social fizeram dos professores de matemática grandes investigadores do ensino e aprendizagem. Refletindo em uma postura crítica e inquietadora frente a sua realidade educativa, o professor passou a ser aquele que busca sempre compreender mais e que questiona sempre o porquê da não obtenção dos resultados esperados.

Nesse novo contexto da Educação e de práticas pedagógicas, em especial da matemática, 
isso foi necessário para que o professor tivesse um olhar mais criterioso e investigativo sobre o seu fazer, procurando sempre melhor compreender os fenômenos da aprendizagem para que todos os alunos pudessem interagir na sala de aula a fim de assimilar os conhecimentos próprios da disciplina. Assim, esses professores precisaram planejar, pensar e trabalhar as aulas de matemática através de leituras sobre temas de interesse dos alunos, da sua realidade cultural para que esses pudessem identificar situações do contexto sociocultural e, assim, identificar e explorar a presença da matemática em situações cotidianas e mais amplas que as cartesianas de sala de aula.

Os alunos, sujeitos do conhecimento, encontram o respaldo necessário para fazer da parceria com o educador o que se mostra essencial para o sucesso dos objetivos pretendidos pela disciplina. Considerando-se todas as subjetividades que estão na base dessa prática, os alunos acabam sendo responsáveis diretos na busca da construção conceitual e prática dos conteúdos. Freire afirma que:

não é possível a educadoras e educadores pensar apenas os procedimentos didáticos e os conteúdos a serem ensinados não podem ser totalmente estranhos àquela cotidianidade. $\mathrm{O}$ que acontece, no meio popular, nas periferias das cidades, nos campos - trabalhadores urbanos e rurais reunindo-se para rezar ou para discutir seus direitos, nada pode escapar à curiosidade arguta dos educadores envolvidos na prática da educação popular (FREIRE, 1995, p. 13).

Focando o desenvolvimento de uma metodologia onde o professor pudesse estar mais próximo do cotidiano do aprendiz e dos problemas que esse enfrenta, emergiram a modelagem matemática, a modelação matemática e a teoria dos jogos. A modelagem e a modelação matemática oportunizaram o rompimento da dicotomia existente entre a matemática da instituição formal e a vida cotidiana.

Segundo Caldeira (2000), a modelagem matemática não deve ser utilizada apenas para justificar o conteúdo que está sendo ensinado, mas deve também valorizar a razão, o motivo pelo qual o aluno deve aprender matemática e a importância que isso representa na formação dele como cidadão responsável e participativo na sua sociedade. Daí, a relevância de um ensino que se mostre significativo e favoreça a aprendizagem dos alunos de forma integradora ao seu contexto social. Já a modelação nos permite encarar um problema real e considerar situações do dia-a-dia com a qual nossos alunos se deparam, permitindo-lhes estar aptos a resolver tais problemas valendo-se de 
conhecimentos matemáticos. A proposta dos jogos matemáticos é a de que esses possibilitem ao aluno o desenvolvimento de estratégias de raciocínio, estimativa e o cálculo mental.

Retomando à Etnomatemática, ainda que ela seja uma linha de estudo bastante recente e inovadora, é preciso ter em mente seu potencial e suas características específicas, pois essas permitem a valorização da matemática considerando diferentes grupos socioculturais, reconhecendo os conceitos matemáticos informais edificados pelos alunos através das experiências fora do contexto escolar.

D’Ambrosio nos apresenta três vertentes internas como sendo uma possibilidade do trabalho matemático. A primeira é aquela em que o educador parte para conhecer um grupo social ou cultural e, depois de uma descrição etnográfica, sugere um modelo educacional que dialogue com o grupo estudado e o conduza à matemática escolar. Outra vertente reside na descrição feita pelo próprio grupo e, nesta situação particular, o pesquisador não interferirá, possuindo apenas a oportunidade de apresentar, num diálogo acadêmico, os resultados da investigação.

Neste estudo nos deteremos na terceira vertente, pois esta se aproxima mais da realidade pesquisada a partir da visão do grupo estudado. Entendo que, por esse caminho, os grupos socioculturais em pauta mantêm sua autonomia, no que tange às decisões. Como sugere Knijnik aos educadores, "nosso desafio é enraizar a educação matemática na cultura; cultura aqui entendida como algo que as pessoas e os grupos sociais produzem e que não está de uma vez por todas fixa, determinada, fechada nos seus significados" (2000, p. 50). Isso pode ser alinhado ao pensamento de Morin (2000), quando ele sugere que todo conhecimento comporta o risco do erro e da ilusão. A etnomatemática aparece, então, para nós, educadores, enquanto alternativa inovadora e significativa de trabalho com potencial de lograr grandes descobertas e avanços no ensino.

Vive-se uma nova era do conhecimento, veloz, multiplicativo. Diante disso, não faz mais sentido caminhar lentamente, assumindo uma postura de meros transmissores de conhecimentos, ultrapassados e deslocados da realidade. É preciso que se estimule nos alunos, uma consciência crítica capaz de resolver problemas do lugar onde vivem e de mudar a realidade social. Portanto, é fundamental que se busque compreender os significados subjacentes no cotidiano dos alunos para entender as implicações e consequências que fazem parte de relações socioculturais desse cotidiano. 
Pensando, então, articulação entre os saberes provenientes da cultura dos alunos, Monteiro e Pompeu (2001, p. 54) afirmam que

[...] o processo educacional deve estar atento ao reconhecimento e ao respeito do saber presente no cotidiano do grupo, e também deve ter o compromisso de possibilitar acesso a outros conhecimentos, permitindo ao grupo olhar através de outra perspectiva. Nesse exercício de experienciar o novo e novamente voltar o olhar pela sua perspectiva, examinando-os simultaneamente, a fim de conhecer as semelhanças, as diferenças e estabelecendo relações, o grupo apropria-se do novo, porém, pleno de opções e certamente com possibilidades de criar um outro saber que não pertence nem à sua cultura nem a cultura de quem influenciou.

Assim, conhecer as experiências que compõem a vida cotidiana e as subjetividades dos alunos para estabelecer relações com a escola e o mundo do trabalho pode ser um caminho para a discussão de novas formas de organização e estruturação da instituição escolar. $O$ ensino de matemática deve ser indissociável da história da humanidade, o que torna necessário conhecer o caráter coletivo, dinâmico e processual da produção de conhecimento que ocorre de acordo com as necessidades e anseios dos indivíduos. Enquanto a matemática se mantiver contrária ao que os alunos fazem ou sabem e não estabelecer ligações entre esse saber exigido pela escola, não encontraremos, nesse ensino, um espaço para desenvolver uma estratégia educativa que atue no campo das vivências, valores e identidades culturais.

É fundamental, portanto, explorar o saber matemático como um campo de aplicabilidade em várias áreas do conhecimento, de modo a favorecer a criatividade, o trabalho coletivo, a iniciativa pessoal e a autonomia advinda do desenvolvimento da confiança na própria capacidade de conhecer e enfrentar desafios.

\section{ENCONTRO COM A PRÁTICA REFLETIDA: CAMINHOS METODOLÓGICOS}

Para o alcance dos objetivos propostos neste trabalho, buscamos nesta pesquisa do tipo qualitativa um referencial teórico e metodológico que sustentasse o nosso fazer e, por conseguinte, podermos aproximar melhor e com mais qualidade subjetiva do objeto em discussão. Esse tipo de pesquisa percebe e respeita o contexto em que os sujeitos estão envolvidos, tanto os pesquisados 
quanto os pesquisadores. Além disso, oportuniza a flexibilidade acerca dos achados contribuindo para outras discussões e até mesmo contribuindo às pesquisas já em andamento.

A pesquisa foi realizada com estudantes do $6^{\circ}$ ano das cinco salas existentes no turno matutino, incluindo a professora de matemática que leciona nessas turmas. O grupo de alunos com o qual se realizou a parte empírica desta pesquisa consistia em 40 alunos, sendo 22 do sexo masculino e 18 do sexo feminino e mais de 50\% residem na zona rural do município. A escola desde a sua fundação em 1997 foi construída com o objetivo de atender alunos da zona rural que estudam em suas comunidades e apenas oferecem até o $6^{\circ}$ ano do Ensino Fundamental. Hoje, são atendidos mais de seiscentos alunos sendo, aproximadamente, 480 alunos de 22 comunidades rurais diferentes no turno matutino. A faixa etária dos sujeitos envolvidos varia entre 10 e 15 anos, filhos de trabalhadores rurais, pescadores e pequenos comerciantes. Um deles tem mais de 16 anos.

No contato inicial e enquanto explicava os motivos da pesquisa alguns já pontuavam não gostar da matemática. Alegavam que se tratava de uma disciplina chata e cansativa. Isso reforça a proposta que venho tratando neste texto a respeito da importância de buscar alternativas que relacionem os aspectos da cultura dos alunos da zona rural com o cotidiano da sala de aula. Pensando nisso, D’Ambrosio (1998, p. 121) propõe que a etnomatemática substitua o já desgastado modelo de ensino baseado numa relação obsoleta de causa e efeito. A essência de sua proposta é:

Uma educação universal, atingindo toda a população, propiciando a todos o espaço adequado para o pleno desenvolvimento de criatividade desinibida, que ao mesmo tempo em que preserva a diversidade e elimina as iniquidades, conduz a novas formas de relação intra e interculturais sobre as quais se estruturam novas relações sociais e uma nova organização planetária.

Analisando relatos de alguns alunos, percebe-se que a matemática é uma presença constante nas atividades que os educandos desenvolvem em sua comunidade e que sob a mais simples atividade pode esconder-se um significado matemático ou explicação matemática. Percebe-se, desse modo, a possibilidade de se efetivarem ações pedagógicas a partir de análises orientadas segundo as necessidades e histórias de vida dos discentes, proporcionando uma conexão entre os saberes matemáticos presentes nas atividades que os mesmos realizam na sua comunidade e os saberes matemáticos escolares. Nesse sentido, Marques afirma que: 
Os processos de aprendizagem inserem-se inevitavelmente em comunidades comunicativas e públicas em que os homens aprendem uns dos outros e uns com os outros, da mesma maneira como os conhecimentos por que se orientam especificam-se à medida que se inserem em espaços públicos internos a cada diferençado campo de saber (MARQUES, 1995, p. 29).

Relacionar as práticas pedagógicas com as práticas cotidianas do grupo social ao qual o aluno pertence pode atribuir melhor sentido à aprendizagem da matemática e esta ser menos angustiante tanto para o discente como também para o docente que passa horas do seu tempo preparando aulas com a intenção de promover a participação e a aprendizagem dos alunos. Mas, para sua frustração, no momento da aula, a mesma acaba por se tornar chata conforme narram alguns alunos envolvidos da pesquisa. Portanto, uma aula que não motiva os educandos e não promove uma verdadeira aprendizagem não tem sentido significativo para sua vida real.

Durante a pesquisa constatou-se que dos alunos entrevistados, $55 \%$ (cinquenta e cinco por cento) afirmaram não gostar de estudar matemática porque acham tudo muito difícil e "têm dor de cabeça, só em assistir as aulas”. Os alunos disseram ainda que a matemática que eles têm contato fora da escola é totalmente diferente da que eles estudam na escola com o livro didático. Dizem que prestam atenção nas aulas, mas não conseguem aprender muito ou quase nada.

Os outros 45\% (quarenta e cinco por cento) que afirmaram gostar da matemática, quando questionados, responderam que precisam da matemática para o dia a dia, pois ajudam seus familiares. Um deles citou que o avô tem uma mercearia e ele faz as contas para o avô, "porque o vovô não sabe contar”. Sobre isso, D’Ambrosio (2001) reconhece, como etnomatemática, as práticas matemáticas dos feirantes e outras situações práticas do cotidiano e enfatiza que a utilização dos recursos da comercialização informal revela práticas apreendidas fora do ambiente escolar - uma verdadeira Etnomatemática do comércio.

Um dos entrevistados, narra que o pai tem um parque de vaquejada ${ }^{2}$ e que ele ajuda na venda de senhas e premiação nos eventos. Outros afirmaram gostar de matemática porque fazem contas. Essas declarações nos evidenciam que a matemática só irá se tornar importante para os alunos

\footnotetext{
2 A vaquejada é uma atividade cultural do nordeste brasileiro na qual dois vaqueiros, montados em um cavalo, têm de derrubar um boi puxando-o pelo rabo entre duas faixas de cal do parque de vaquejada.
} 
quando há uma aplicabilidade desta disciplina no contexto real no qual eles estão inseridos.

Quanto aos conteúdos trabalhados na escola, ao serem questionados sobre quais deles veem no dia a dia, de forma unânime responderam as quatro operações fundamentais: adição, subtração, divisão e multiplicação. Também citaram a porcentagem. Em seguida, quais conteúdo do dia a dia eles viam retratados nas aulas de matemática, uma aluna não respondeu, os demais afirmaram que veem as formas geométricas e as quatro operações. Sobre a metodologia adotada nas aulas, eles disseram gostar quando a professora pede para abrir o livro ou quando ela está no quadro explicando multiplicação e frações.

A professora leciona para as cinco turmas dos $6^{\circ}$ ano da escola no turno matutino, é pedagoga e atualmente faz licenciatura em matemática à distância, tendo atuado nesta disciplina nos últimos oito anos. Para ela, os aspectos que mais interferem na aprendizagem dos alunos são a falta de leitura no momento da resolução de situações-problemas e, consequentemente, a falta de interesse na hora das aulas uma vez que os alunos estão quase sempre dispersos. Quando questionada sobre quais estratégias utiliza para amenizar essas dificuldades, a professora disse que faz técnicas de leitura numéricas que estimulam os alunos proporcionando um encadeamento lógico. Segundo ela, "os alunos apresentam bastantes difículdades com a resolução de problemas".

Em seguida, quando indagada sobre a maneira que ela compreende a disciplina, enquanto parte do cotidiano social e da realidade dos seus alunos, a educadora respondeu que a vê como parte fundamental, essencial e indispensável tanto para o nosso cotidiano quando para o dos alunos.

Quanto a seleção dos conteúdos, a metodologia e os recursos utilizados nas aulas, a professora revelou que a sequência dos conteúdos caminha de acordo com a realidade e a necessidade dos discentes, procurando sempre trabalhar em grupos, com utilização de jogos educativos, bingo e calculadoras. Ainda sobre a metodologia, ao ser indagada sobre qual seria a mais eficiente para aprendizagem dos alunos da escola, a educadora afirma que o mais importante é trabalhar de modo que desperte o senso crítico, criativo, solidário, significativo e prazeroso dos alunos atendendo às suas necessidades de aprendizagem.

Pode-se perceber na fala da professora uma vontade de inovar e trabalhar de uma forma criativa e que atraia a atenção dos alunos. No entanto, em sua prática de ensino, verifica-se uma 
tendência ao tradicionalismo. Isso talvez seja devido a sua formação acadêmica e a metodologia aprendida que se centra no quadro e no uso do livro didático.

Embora, em alguns momentos, a educadora tente inovar com o uso de jogos, calculadora e bingo, as aulas parecem ainda não prender a atenção dos alunos fazendo com que eles se dispersem com facilidade. O que nos deixa mais convictos de que uma proposta da etnomatemática seria mais consonante com a realidade dos alunos, pois, procurará delinear possíveis caminhos que valorizam os sentimentos de desejos, a cultura e o meio social dos alunos, de modo que o educando possa usar de forma mais adequada os conhecimentos matemáticos trazidos do meio deles para escola.

\section{CAMINHOS POSSÍVEIS PARA UM TRABALHO MAIS INCLUSIVO}

Através do diálogo com os alunos, o professor poderá conhecer a cultura e os desejos deles. Já que são de comunidades rurais distantes, a partir das conversas o professor fará reflexões que se refletirão no planejamento das aulas. É nessa aula diferenciada e com a troca de experiências resultante do diálogo contínuo entre professor e aluno que se desenha a etnomatemática. Assim, as distâncias entre os alunos e a disciplina são encurtadas e assumem uma perspectiva mais inclusiva.

Para adquirir esse novo olhar, é necessário que o professor se livre dos medos e preconceitos, deixando de lado os dogmas relacionados ao ensino tradicional. Considerada uma etnociência, segundo D’ Ambrosio (1990), a etnomatemática relaciona diretamente os fenômenos científicos e tecnológicos com a formação cultural, econômica e social de um determinado grupo e as relações entre diversos grupos. O respeito às diferenças, nesse contexto, é fundamental.

Diante do exposto pelos alunos durante a pesquisa, pode-se constatar que algumas atividades desenvolvidas na comunidade destacam algumas ideias matemáticas não convencionais, mas que quando analisadas com um olhar da etnomatemática demonstram ser métodos facilitadores das suas atividades diárias. A etnomatemática mantém vivos esses etnoconhecimentos e incorpora-os à ação pedagógica. Essa proposta de ação pedagógica permite compatibilizar formas culturais e reduzem ao mínimo as possibilidades de conflito no ensinar da matemática acadêmica.

Para Brousseau (1998) o contexto de ação é determinante na constituição do processo de 
produção do conhecimento, pois o contexto é um critério importante sobre os saberes que o aluno pode ou não mobilizar para a sua ação cognitiva. Os critérios de validação de ação do pensamento dos discentes advêm sobretudo da situação à qual eles estão submetidos, da representação que possuem desta situação, e, em especial, do conjunto de regras que estruturam as relações em um dado contexto.

O principal objetivo da educação matemática é o desenvolvimento de habilidades e competências para que os educandos sejam capazes de resolver situações presentes na sua comunidade e em outros ambientes. É importante que o pensamento do professor esteja sempre voltado para o preparo do aluno para a vida e para o exercício da cidadania o que tornar-se difícil caso o educador se limite a ensinar somente o resolver de problemas propostos pelo livro didático.

\section{POR FIM, SEM CONCLUIR ...}

Sabe-se que a escola deve propiciar um ambiente de construção coletiva. Percebe-se que as pretensões ensaiadas por D’Ambrosio, principal referencial teórico desta pesquisa, constituem-se de grande valor para a práxis educativa que se propõe desenvolver. Através da proposta da etnomatemática, procura-se ajudar os alunos a estabelecerem uma relação entre o conteúdo científico e o seu conhecimento prévio. Procura-se, também, levá-los a compreender que a matemática não é direcionada somente aos números ou às contas, como eles mesmo citaram na pesquisa, mas, sobretudo, às relações do dia-a-dia da comunidade no seu aspecto histórico-cultural, social e econômico.

Por meio da etnomatemática, é possível entender a lógica dos cálculos espontâneos dos alunos, motivando-os na busca de novos conhecimentos e novas construções do pensamento lógicomatemático a partir do que já sabem. Os dados produzidos a partir dos questionários trouxeram contribuições para pensar a formação continuada da professora da turma que desconhecia a opinião dos alunos sobre as aulas de matemática. O fato dos questionários abordarem o contexto dos alunos e a aplicabilidade da matemática no seu cotidiano fez com que fosse possível ter sua atenção e envolvimento, bem como permitiu que compreendessem o real sentido da disciplina matemática. 
Dessa forma, o processo de ensino e aprendizagem de matemática assumindo a perspectiva etnomatemática na educação básica poderá contribuir para o avanço cognitivo, social e cultural dos alunos. Para isso, faz-se necessário que o professor conheça a realidade dos seus alunos, sua vida na comunidade, suas pretensões com a escola e com o ensino de matemática.

\section{REFERÊNCIAS}

BROUSSEAU, G. Théorie des situations didactique. Grenoble: La Pensé e Sauvage, 1998.

CRESWELL, J. W. Investigação qualitativa e projetos de pesquisa. Trad. Sandra Mallmann. Porto Alegre: Penso, 2014.

D'AMBROSIO, U. Da realidade à ação: reflexões sobre educação e matemática. São Paulo: Summus Editorial, 1986. . Etnomatemática: arte e técnica de aprender. São Paulo: Ática, 1990.

. Etnomatemática: um programa. Educação Matemática. v.1, n.1, 1993a, pp. 05-11.

. Etnomatemática: arte ou técnica de explicar e conhecer. São Paulo: Ática,1993b.

. Educação matemática: da teoria à prática. São Paulo: Papirus, 1996.

. Etnomatemática. São Paulo: Ática, 1998.

. Etnomatemática: elo entre tradição e ciência. Belo Horizonte: Autêntica, 2001.

FOSSA, J. A. Presenças matemáticas. Natal: EDUFRN, 2004.

FERREIRA, E. S. Etnomatemática: uma proposta metodológica. Rio Janeiro: Santa Úrsula, 1997.

FREIRE, P. Educação de adultos, algumas reflexões. In: GADOTTI, M.; ROMÃO, J. (Orgs.). Educação de jovens e adultos: teoria, prática e proposta. São Paulo: Cortez, 1995.

KNIJNIK, G. Etnomatemática na luta pela terra: uma educação que mexe com as tripas das pessoas. In: FOSSA, J. A. (Org.). Facetas do diamante: ensaios sobre educação matemática e história da matemática. Rio Claro: SBHMat, 2000.

MARQUES, M. O. A aprendizagem na mediação social do aprendizado e da docência. Ijuí: Unijuí, 1995.

MONTEIRO, A.; POMPEU, G. A matemática e os temas transversais. São Paulo: Moderna, 2001. 
MORIN, E. Os sete saberes necessários à educação do futuro. São Paulo: Cortez, 2000.

ROHDEN, H. Educação do homem integral. São Paulo: Martin Claret, 1998. 